\title{
Gemeinsamer Kongress der Dreiländertagung Angiologie und der Jahrestagung Phlebologie mit dem Dresden Congress Award 2018 ausgezeichnet
}

Am 15.11.2018 hat Prof. Dr. Norbert Weiss als Tagungspräsident der Dreiländertagung der deutschsprachigen angiologischen Fachgesellschaften stellvertretend für das gesamte Kongressteam des Jahres 2016 vom Dresdner Oberbürgermeister den Dresden Congress Award 2018 in der Kategorie „weiter gedacht“ verliehen bekommen. Der Preis wurde aus über 100 Bewerbungen von Kongressausrichtern in Dresden zwischen August 2016 und August 2018 ausgewählt.
Insgesamt sind 6 Preise in 6 Kategorien vergeben worden.

Mit dem Dresden Congress Award, auch „Oscar“ der Kongressbranche genannt, ehrt die Landeshauptstadt Dresden gemeinsam mit der Dresden Marketing $\mathrm{GmbH}(\mathrm{GmbH})$ und der Unterstützung der Dresdner Kongressbranche mittlerweile zum zwölften Mal engagierte Wissenschaftler, Unternehmer und Veranstalter, die Kongresse und Tagun- gen in die sächsische Landeshauptstadt geholt haben.

Die Dreiländertagung Angiologie zusammen mit der Jahrestagung der Deutschen Gesellschaft für Phlebologie wurde aufgrund des innovativen Konzeptes ausgewählt, eine multinationale und multidisziplinäre Fachtagung über Fachgesellschaftsgrenzen hinaus organisiert zu haben, die Brücken geschlagen hat, einerseits zwischen Fachge-

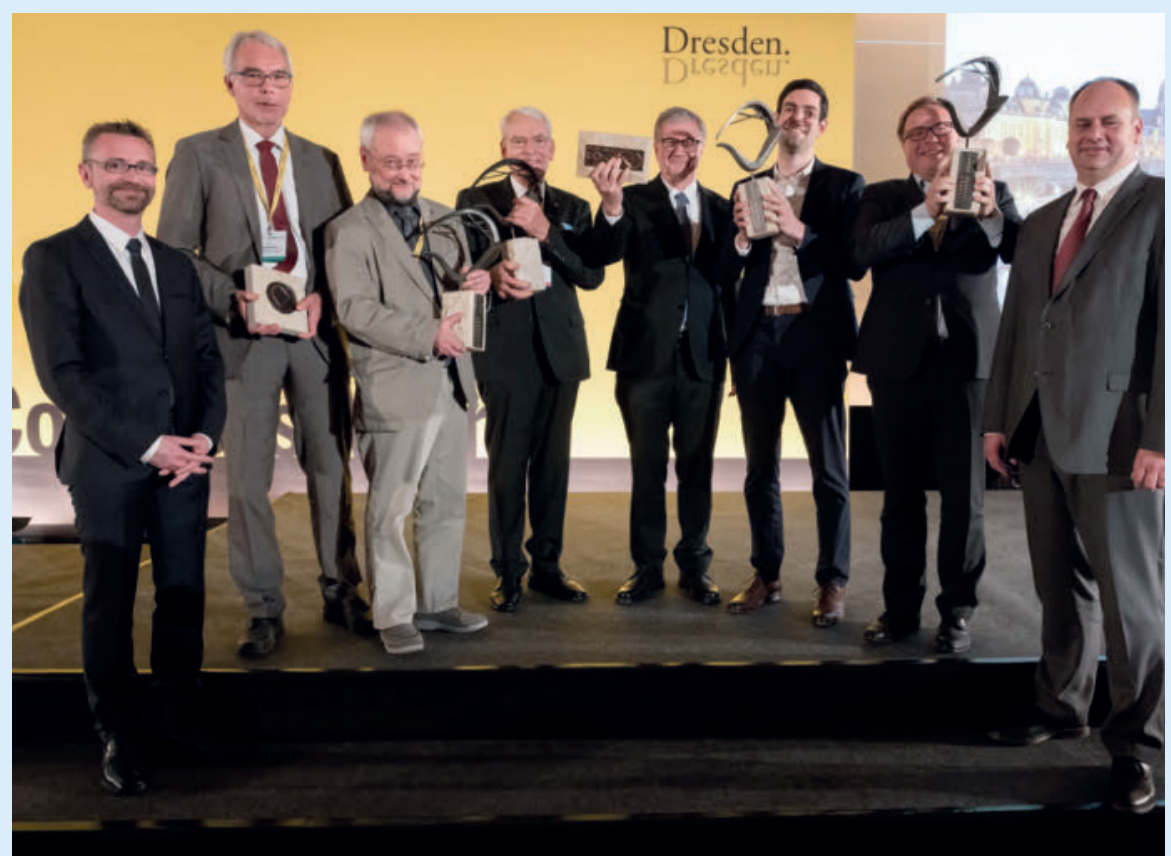

Abb. 1 Das Siegerfoto 2018. Weitere Informationen zum Preis unter: https://www.dresdenconvention.com/dresden-congress-award/gewinner-2018 (Quelle: Dresden Marketing GmbH, (c) BLEND 3/ Frank Grätz).

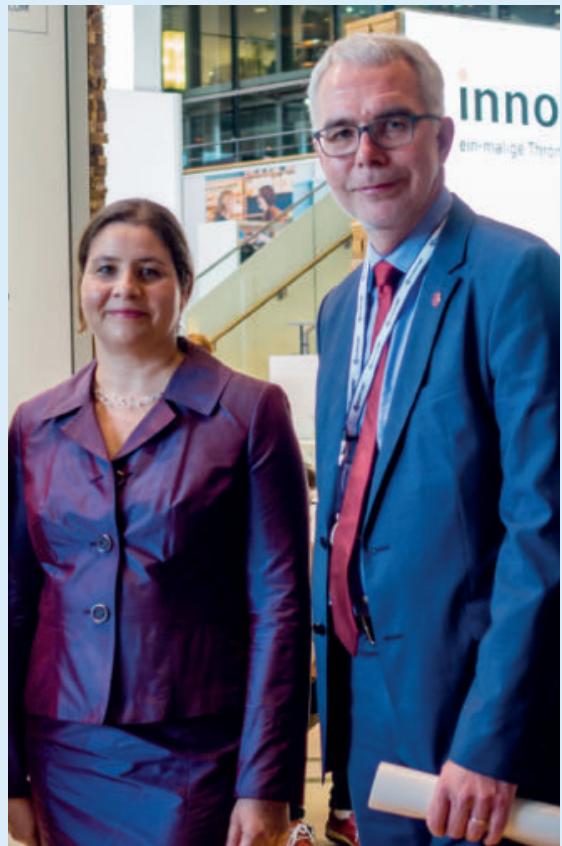

-Abb. 2 Kongresspräsidenten von 2016: Prof. Dr. Stefanie Reich-Schupke und Prof. Dr. Norbert Weiss 


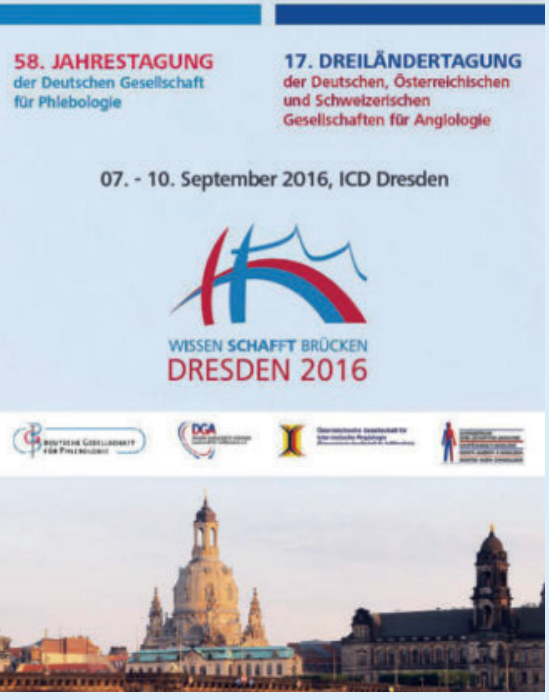

Abb. 3 58. Jahrestagung der DGP und 17. Dreiländertagung Angiologie 2016 in Dresden sellschaften, die ähnliche Ziele verfolgen, und andererseits zwischen klinischer Versorgung, Grundlagenforschung und klinisch orientierter Forschung.

Das Organisationsteam aus dem Jahr 2016 freut sich sehr über diese Anerkennung des offenbar erfolgreich und nachhaltig umgesetzten Tagungsmottos „WissenSchaf(f)t Brücken“. Dass dieses Konzept als „weiter gedacht" wahrgenommen und ausgezeichnet worden ist, sollte unserer Ansicht nach Ansporn sein, um mit den Freunden und Kollegen anderer gefäßmedizinischer Fachgesellschaften in Kontakt zu bleiben und über weitere gemeinsame Projekte und Tagungen nachzudenken.

Für das Organisationsteam 2016 Stefanie Reich-Schupke
IMPRESSUM

Verantwortlich für Mitteilungen der DGP:

Dr. med. Erika Mendoza 